\title{
Melatonin Alleviates Age-Associated Endothelial Injury of Atherosclerosis via Regulating Telomere Function
}

\author{
Yinghua $\mathrm{Xie}^{1, *}$ \\ Danfei Lou ${ }^{2} *$ \\ Daimin Zhang ${ }^{3}$ \\ 'Department of Geriatrics, Fuzhou NO.I \\ Hospital Affiliated with Fujian Medical \\ University, Fuzhou, Fujian, 350009 , \\ People's Republic of China; ${ }^{2}$ Department \\ of Geriatrics, Shanghai Municipal Hospital \\ of Traditional Chinese Medicine, Shanghai \\ University of Traditional Chinese \\ Medicine, Shanghai, 20007I, People's \\ Republic of China; ${ }^{3}$ Department of \\ Cardiology, Nanjing First Hospital, \\ Nanjing Medical University, Nanjing, \\ Jiangsu, 210006, People's Republic of \\ China
}

*These authors contributed equally to this work
Correspondence: Daimin Zhang Department of Cardiology, Nanjing First Hospital, Nanjing Medical University, NO. 68 Changle Road, Nanjing, Jiangsu, 210006 , People's Republic of China

$\mathrm{Tel} / \mathrm{Fax}+86$ 25-5227|34I

Email zhangdmun@I26.com
Background: Atherosclerosis is an aging-related disease, partly attributed to telomerase dysfunction. This study aims to investigate whether telomere dysfunction-related vascular aging is involved in the protection mechanism of melatonin (MLT) in atherosclerosis.

Methods: Young and aged $\mathrm{ApoE}^{-/-}$mice were used to establish atherosclerotic mice model. H\&E staining and immunofluorescence assay were performed to detect endothelial cell injury and apoptosis. Inflammatory cytokines and oxidative stress-related factors were determined using corresponding commercial assay kits. Telomerase activity was detected by TRAP assay, and SA- $\beta$-gal staining was conducted to evaluate cellular senescence. HUVECs were treated with $\mathrm{H}_{2} \mathrm{O}_{2}$ for $1 \mathrm{~h}$ to induce senescence. Western blot was performed to measure protein expression.

Results: An obvious vascular endothelial injury, reflected by excessive production of inflammatory cytokines, elevated ROS, MDA and SOD levels, and more apoptotic endothelial cells, was found in atherosclerotic mice, especially in aged mice, which were then greatly suppressed by MLT. In addition, telomere dysfunction and senescence occurred in atherosclerosis, especially in aged mice, while MLT significantly alleviated the conditions. CYP1A1, one of the targeted genes of MLT, was verified to be upregulated in atherosclerotic mice but downregulated by MLT. Furthermore, $\mathrm{H}_{2} \mathrm{O}_{2}$ induced a senescence model in HUVECs, which was accompanied with a remarkably increased cell viability loss and apoptosis rate, and a downregulated telomerase activity of HUVECs, and this phenomenon was strengthened by RHPS4, an inhibitor of telomerase activity. However, MLT could partly abolish these changes in $\mathrm{H}_{2} \mathrm{O}_{2}$ - and RHPS4-treated HUVECs, demonstrating that MLT alleviated vascular endothelial injury by regulating senescence and telomerase activity.

Conclusions: Collectively, this study provided evidence for the protective role of MLT in atherosclerosis through regulating telomere dysfunction-related vascular aging.

Keywords: melatonin, atherosclerosis, telomere, vascular aging, senescence

\section{Introduction}

Atherosclerosis, a chronic progressive arterial disease, is a multifactorial and complicated disease involving multiple cellular dysfunctional responses, such as vascular smooth muscle cell proliferation, foam cell formation and endothelial cell injury, becoming the primary cause of cardiovascular diseases (CVD). ${ }^{1}$ For the past 50 years, CVD have been the most common cause of death among the aged worldwide, and by 2030, approximately $20 \%$ of the population will be over 65 years old, which is expected to lead to $40 \%$ of all deaths. ${ }^{2-4}$ Epidemiological 
evidence indicates that aging, especially vascular aging, is one of the major and independent risk factors for the development of atherosclerosis, ${ }^{5}$ highlighting the need to gain deeper insight into the molecular mechanism underlying vascular aging to discover new therapeutic targets.

Telomere is a kind of DNA protein complex that covers the end of eukaryotic chromosomes. Although it has no biological functions such as transcription and translation, telomere is an essential structure for maintaining cell proliferation and genome stability, which is responsible for telomere replication and elongation. Telomere is recognized as the biological clock of cellular aging, and telomere shortening is a key biomarker of the onset of senescence. ${ }^{6}$ Emerging evidence declare that telomere lengthening extends cell lifespan and prevents from endothelial dysfunction associated with senescence. ${ }^{7}$ Dysfunction of endothelial cells is an initial factor of atherosclerosis. As expected, Minamino et al uncovered that vascular endothelial cells with senescence-associated phenotypes are observed in human atherosclerotic lesion, which may be attributed to telomere shortening. ${ }^{8}$ In addition, telomerase is a reverse transcriptase enzyme, which is necessary for proper function of telomeres. Decreased telomerase activity occurs in the process of endothelial cell dysfunction and atherosclerosis, and up-regulation of telomerase activity in endothelial cell might be one mechanism contributing to the atheroprotective effect of potential drugs. ${ }^{9-11}$ Thus, given the close association among telomerase activity, senescence and atherosclerosisrelated endothelial cell dysfunction, targeting telomeretelomerase function may be a promising direction to further understand the pathogenesis of $\mathrm{AS}$, so as to develop more effective drugs.

Melatonin (MLT; $N$-acetyl-5-methoxytryptamine) is a multifunctional hormone mainly produced by the pineal gland that plays a vital role in regulating sleep and circadian rhythm. ${ }^{12}$ The secretion of MLT is reduced with aging and in certain diseases, indicating deregulation of MLT may be associated with the development of human diseases. With deep research, more and more properties of MLT have been found, including anti-oxidant, anti-inflammatory, anticancer and neuroprotective activities, and extensive evidence reveal that MLT plays a protective role in respiratory diseases, cancers, neurodegenerative diseases, as well as various cardiovascular diseases including heart failure, hypertension, ischemia-reperfusion injury and atherosclerosis. ${ }^{13-19}$ At present, the protective effects of MLT on atherosclerosis have been widely reported, and potential mechanism of action has been also widely explored; however, up to date, whether telomere-telomerase function is involved in its protection mechanism in atherosclerosis remains unclear.

Interestingly, we found that human cytochrome P450 1A1 (CYP1A1) is one of the targeted genes of MLT by search STITCH website (http://stitch.embl.de/). CYP1A1 is involved in multiple metabolic activation, leading to production of reactive intermediates, eventually resulting in cellular dysfunction and disease development. ${ }^{20}$ Recent years, CYP1A1-mediated metabolic activation was considered to be a direct mechanism for atherosclerosis. ${ }^{21}$ A positive correlation between upregulated expression of human telomerase reverse transcriptase (hTERT), the telomerase catalytic subunit and CYP1A1 was observed in human lung cancer, indirectly suggesting that CYP1A1 might be associated with telomere-telomerase function. ${ }^{22}$

Based on these findings, we hypothesize that MLT may exert its protective function in vascular aging of atherosclerosis through targeting CYP1A1-mediated telomeretelomerase function. We aim to verify this hypothesis by conducting a series of in vivo and in vitro experiments. This study will provide a novel molecular mechanism underlying the development of atherosclerosis, and provide reference for the discovering of antiatherosclerotic drugs.

\section{Materials and Methods}

Animal Model

Eighteen young-male $\mathrm{ApoE}^{-/-}$mice (7 weeks old) and 18 aged-male $\mathrm{ApoE}^{-/-}$mice (8 months old) on a C57BL/6 background were obtained from the Model Animal Research Center of Nanjing University (Nanjing, China), and were used to establish the AS model. All mice were housed on a $12 \mathrm{~h} / 12 \mathrm{~h} \mathrm{light/dark}$ cycle with unlimited access to food and water. After one-week adaptation, the young mice were randomly assigned into three groups: Con-Y (young ApoE ${ }^{-/-}$mice without any further treatment), AS-Y (young ApoE ${ }^{-/-}$mice received high fat diet (HFD; Junke biological Co., LTD, Nanjing, China) for 16 weeks) and MLT-Y (young ApoE ${ }^{-/-}$mice received HFD and intraperitoneally injected with MLT $(20 \mathrm{mg} / \mathrm{kg} / \mathrm{d})$ ). Meanwhile, the aged mice were also divided into three groups: Con-O, AS-O and MLT-O. The mice were euthanized under deep anesthesia by intraperitoneal injection with an overdose of pentobarbital sodium $(200 \mathrm{mg} / \mathrm{kg})$ to obtain their samples. This study was carried out according to the Guide for the Care and Use of Laboratory animals 
and approved by the Ethics Committee of the Nanjing First Hospital.

\section{Histological Analysis}

The blood vessel tissues between thoracic and abdominal aortas were cut off and fixed in $10 \%$ formaldehyde for 24 h. Subsequently, the tissues were embedded in paraffin and cut into sections with $4-\mu \mathrm{m}$-thickness. The sections were stained with hematoxylin and eosin (H\&E). The sections were then observed under an optical microscope (Olympus BX53, Tokyo, Japan).

\section{Immunofluorescence Assay}

A terminal transferase dUTP nick-end labeling (TUNEL) assay with the in situ Apoptosis Detection Kit (Keygen Biotech) was employed to assess apoptosis of tissue. In addition, immunofluorescence assay based on CD31 antibody was simultaneously conducted to localize endothelial cells in blood vessel tissues. In brief, the sections were deparaffinized and hydrated by xylene and ethanol, followed by digestion with Proteinase $\mathrm{K}$ at $55^{\circ} \mathrm{C}$ for $1 \mathrm{~h}$, and incubation with primary antibody against CD31 at $4{ }^{\circ} \mathrm{C}$ overnight. Afterwards, the sections were washed twice with ice-cold PBS, and incubated with TUNEL reaction mixture and secondary anti-rabbit IgG-Alexa Fluor 488 antibody at $37{ }^{\circ} \mathrm{C}$ for $1 \mathrm{~h}$. Subsequently, the sections were stained with DAPI solution at room temperature for $5 \mathrm{~min}$ in the dark. The immunofluorescence images were obtained under an inverted fluorescence microscope (Olympus BX53, Tokyo, Japan).

\section{Cytokine Analysis}

Levels of IL-6 (ml002293), IL-1 $\beta$ (ml063132), TNF- $\alpha$ (ml002095) in blood and tissue homogenate were determined using their corresponding enzyme-linked immunosorbent assay (ELISA) kits (Enzyme-linked Biotechnology, Shanghai, China) according to the manufacturer's instructions. 15-HETE level in tissue homogenate was measured using 15-HETE ELISA kits (534721, Cayman Chemical, Ann Arbor, MI, USA) following the manufacturer's protocol.

\section{Biochemical Indexes Assay}

Levels of malondialdehyde (MDA; A003-1-1), and superoxide dismutase (SOD; A001-1-2) in tissue homogenate were determined using their corresponding commercial kits from Nanjing Jiancheng Bioengineering Institute (Nanjing, China) according to the manufacturer's instructions. The level of ROS of frozen aortic tissue sections were assessed by Frozen Section Reactive Oxygen Species (ROS) Assay Kit (Beijing Baiaolaibo Technology Co., LTD, Beijing, China) in accordance with the manufacturer's protocol and was observed under an inverted fluorescence microscope (Olympus BX53). In addition, the activity of CYP1A1 was detected using P450-Glo ${ }^{\mathrm{TM}}$ CYP1A1 Assay kit (Promega, USA) according to the manufacturer's instructions.

\section{Western Blot}

The blood tissue was homogenized and protein was extracted using RIPA buffer with protease inhibitor cocktail (Roche). After determining the protein concentration using BCA, the same amount of protein $(30 \mu \mathrm{g} /$ lane) was separated on $12 \%$ SDS-PAGE gel and transferred to PVDF membranes. The membranes were blocked in 5\% skimmed milk for $2 \mathrm{~h}$ at room temperature. Subsequently, the membranes were incubated with the primary antibodies against $\operatorname{Bax}(1: 1,000$, ab32503, Abcam), Bcl-2 (1:2, 000, ab182858, Abcam), cleaved caspase 3 (1:1, 000, \#9661, Cell Signaling Technology), and GAPDH (1:2, 500, ab9485, Abcam) at $4{ }^{\circ} \mathrm{C}$ overnight. On the following day, the membranes were washed and incubated with a horseradish peroxidase-conjugated goat anti-rabbit IgG secondary antibody (1:2, 000, ab7090, Abcam) for $2 \mathrm{~h}$ at room temperature. Finally, the bands were visualized using an ECL Western blotting detection kit (Fude Biological Technology, China) and quantified using ImageJ software.

\section{Telomere Length Assay}

Telomere length measurements were performed by Southern blot analysis of the terminal restriction fragments as described previously. $^{23}$ In brief, genomic DNA extracted from cells were digested with $R s a \mathrm{I}$ and Hinfl (Thermo Fisher Scientific), resolved in 0.5\% agarose gels for $24 \mathrm{~h}$ at $40 \mathrm{~V}$, electrophoresed and transferred onto positively charged nylon membranes (Roche Diagnostics $\mathrm{GmbH}$ ). After the incubation with a digoxigenin-labeled telomeric probe at $42^{\circ} \mathrm{C}$ overnight for hybridization, the membranes were washed, incubated with an alkaline phosphatase conjugated anti-digoxigenin-antibody, and then exposed to alkaline phosphatase conjugate cleavage of chemiluminescent CDP-Star substrate solution for visualization. 


\section{Telomerase Activity Assay}

Telomere repeat amplification protocol (TRAP) assay was performed to quantify telomerase activity as described previously. ${ }^{24}$ Briefly, total protein of tissue or cells were extracted and quantified. A protein extract from Hela cells, which contain an active telomerase, was used as a positive control. Each sample was diluted with TRAP buffer and mixed to a $50 \mu \mathrm{L}$ of reaction mixture. Eventually, qPCR was carried out using a Bio-Rad CFX96/C1000 with an initial denaturation at $95^{\circ} \mathrm{C}$ for $2 \mathrm{~min}$ followed by 37 cycles of $95^{\circ} \mathrm{C}$ for $35 \mathrm{~s}, 50^{\circ} \mathrm{C}$ for $35 \mathrm{~s}$, and $72^{\circ} \mathrm{C}$ for $90 \mathrm{~s}$.

\section{Cell Culture and Treatment}

Human umbilical vein endothelial cells (HUVECs) were purchased from the American Type Culture Collection (ATCC, Manassas, VA, USA). The cells were cultured in DMEM (Hyclone, South Logan, USA) with 10\% fetal bovine serum (FBS; Gibco, Grand Island, NY, USA) and $1 \%$ streptomycin/penicillin mixture (Beyotime, Beijing, China) at $37{ }^{\circ} \mathrm{C}$ in a humidified incubator with $5 \% \mathrm{CO}_{2}$.

For the following assay, the cells were initially treated with $60 \mu \mathrm{M} \mathrm{H} \mathrm{H}_{2} \mathrm{O}_{2}$ (Sigma-Aldrich, Merck KGaA) for $1 \mathrm{~h}$ and then incubated for $24 \mathrm{~h}$ at $37{ }^{\circ} \mathrm{C}$ to induce senescence. $^{25}$ To measure the effect of MLT and telomerase activity, cells were incubated with $0.2 \mu \mathrm{M}$ RHPS4 (Selleck), an inhibitor of telomerase activity, along with or without MLT (100 and $500 \mu \mathrm{M}), 30 \mathrm{~min}$ prior to $\mathrm{H}_{2} \mathrm{O}_{2}$ induction.

\section{Cell Viability}

Cell viability was determined using MTT reagent (Beyotime Institute of Biotechnology, Haimen, China) in accordance with the manufacturer's instructions. In brief, HUVECs were grown in 96-well plates. After the indicated treatments, $10 \mu \mathrm{L}$ of MTT solution $(5 \mathrm{mg} / \mathrm{mL})$ was added to each well, followed by incubation at $37{ }^{\circ} \mathrm{C}$ with $5 \% \mathrm{CO}_{2}$ for another $4 \mathrm{~h}$. Subsequently, $200 \mu \mathrm{L}$ DMSO was added to each well to dissolve any crystals, and the plates were agitated for $10 \mathrm{~min}$. The OD values of each well were measured at the wavelength of $490 \mathrm{~nm}$.

\section{Senescence-Associated $\beta$-Galactosidase Activity Assay}

Senescence was measured using a Senescence $\beta$-galactosidase (SA- $\beta$-gal) Staining Kit (C0602, Beyotime Biotechnology, China) according to the manufacturer's instructions. For cell assay, HUVECs were fixed with $2 \%$ formaldehyde for $10 \mathrm{~min}$ at room temperature. After washing with PBS twice, cells were incubated with fresh SA- $\beta$ gal staining solution at $37{ }^{\circ} \mathrm{C}$ overnight. The percentage of SA- $\beta$-gal-positive cells was calculated through counting the positively stained cells. For tissue assay, the frozen sections were prepared to stain according to the kit instruction of SA- $\beta$-gal and the images were observed under an Olympus BX43 microscope (Olympus).

\section{Flow Cytometry Assay}

Cell apoptosis was evaluated by an Annexin V-FITC apoptosis detection kit (KeyGen, Biotech, Nanjing, China) in accordance with the manufacturer's instructions. In brief, after indicated treatment, cells were harvested and washed with cold PBS, and resuspended in a binding buffer. Then, cells were stained with $10 \mu \mathrm{L}$ FITCAnnexin $\mathrm{V}$ and $5 \mu \mathrm{L}$ propidium iodide at room temperature for $30 \mathrm{~min}$ in the dark. Apoptosis was analyzed by flow cytometry (FACSCalibur, Becton-Dickinson) using the Cell-Quest software (Becton-Dickinson).

\section{Statistical Analysis}

Statistical analysis was conducted using Prism GraphPad software version 8.0. The data were presented as mean \pm SD. P values were calculated using one-way ANOVA with Tukey's post hoc analysis. A p value less than 0.05 was considered to statistically significant.

\section{Results}

\section{MLT Alleviates Vascular Aging-Related Endothelial Injury in ApoE ${ }^{-/-}$Mice}

After being administered with HFD and MLT, the effects of MLT on the endothelial injury of blood vessel tissues in young or aged atherosclerotic mice were evaluated. The H\&E staining of blood vessel tissues in each group revealed that the thickness of the aortic wall was uniform in the control group, while the thickness of the aortic wall was non-uniform and the arterial intima thickening was observed in HFD-administered $\mathrm{ApoE}^{-/-}$mice, especially in aged mice. MLT treatment remarkably reduced the arterial intima thickening in both young and aged mice (Figure 1A). In addition, the endothelial cell was marked and localized by CD31, and cell apoptosis was assessed by TUNEL and Western blot. As shown in Figure 1B, the apoptosis mainly occurred at endothelial tissue of the aorta after HFD administration or in aged $\mathrm{ApoE}^{-/-}$mice, compared to young $\mathrm{ApoE}^{-/}$mice, indicating a great 
A

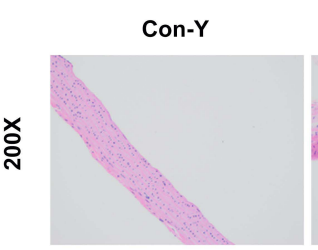

B

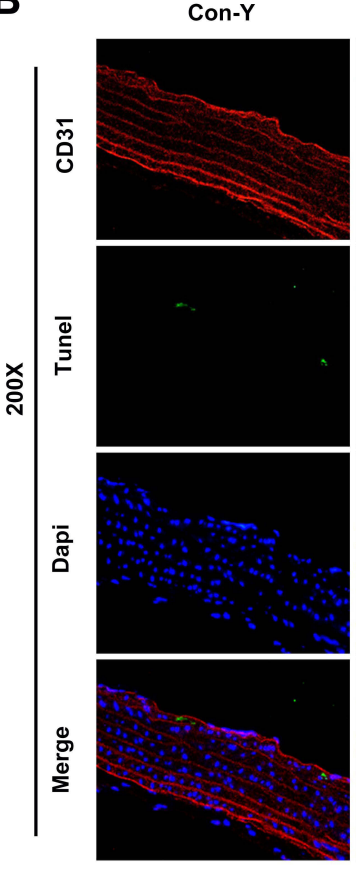

C
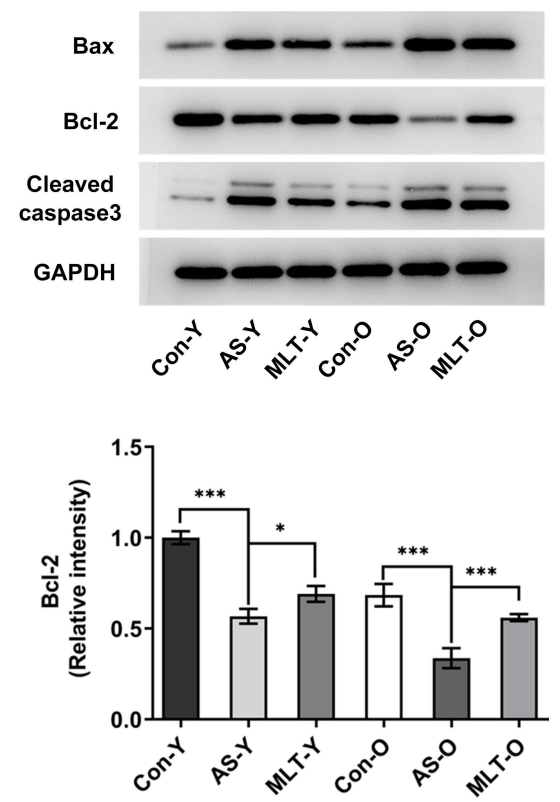

MLT-Y

Con-O

AS-O

MLT-O

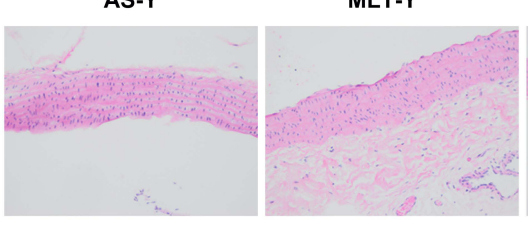

AS-Y

MLT-Y
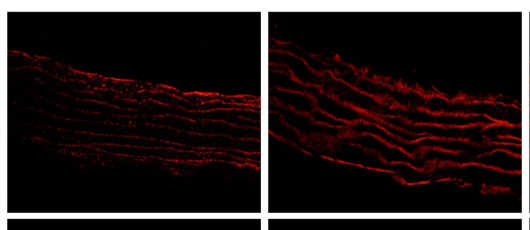

Con-O

AS-O
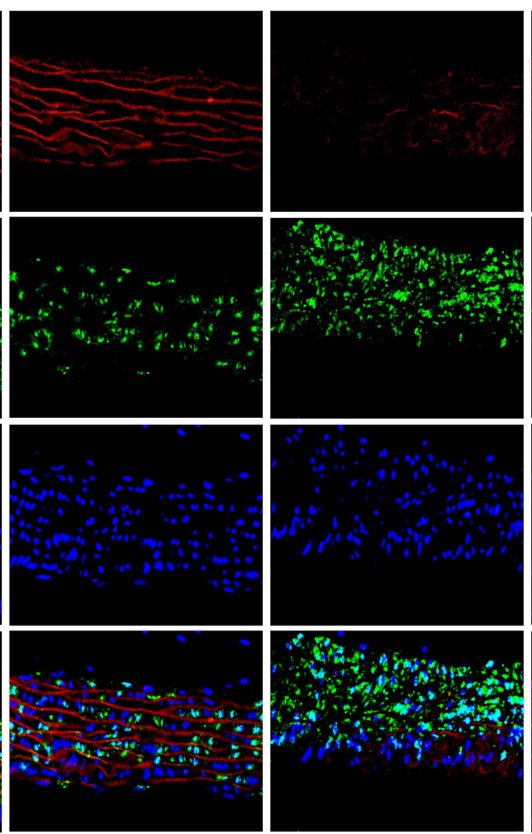

MLT-O
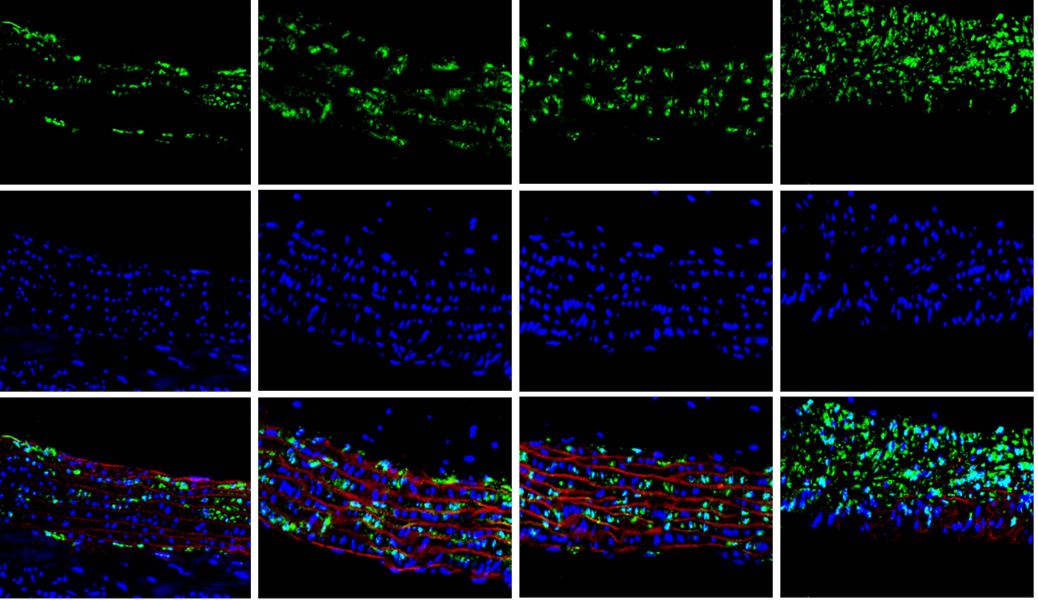
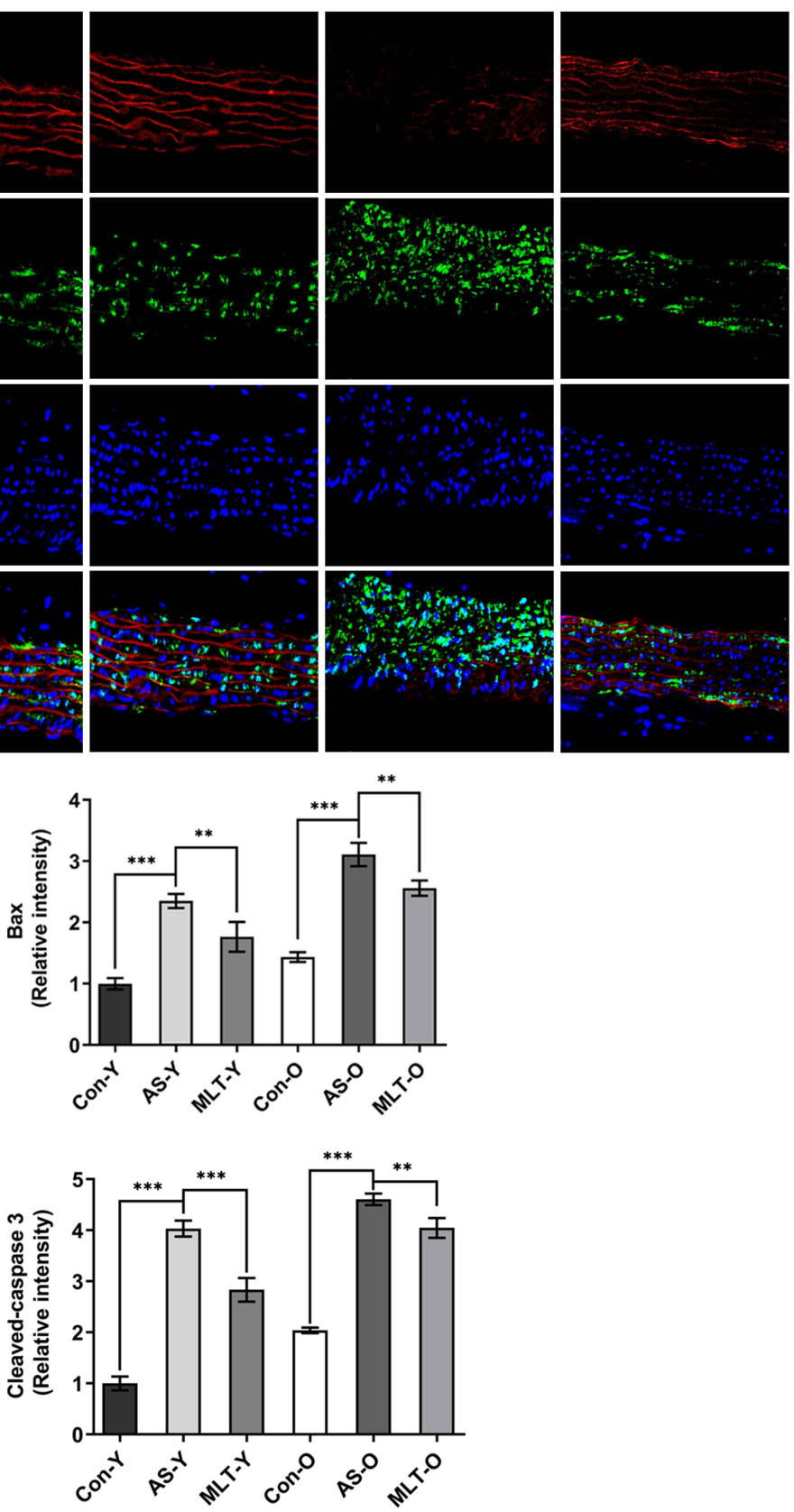

Figure I MLT alleviates vascular aging-related endothelial injury in $\mathrm{ApoE}^{-1-}$ mice. Young-male ApoE ${ }^{-1-}$ mice and aged-male ApoE ${ }^{-l-}$ mice were received high fat diet (HFD) to induce atherosclerosis and intraperitoneally injected with melatonin (MLT; $20 \mathrm{mg} / \mathrm{kg} / \mathrm{d}$ ) for treatment. (A) H\&E staining of intima of aorta, magnification $\times 200$. (B) TUNEL staining of intima of aorta, magnification $\times 200$. (C) Western blot and statistical analysis of protein expression of Bax, $\mathrm{Bcl}-2$ and cleaved caspase3. $\mathrm{N}=3$. $*, * *, * * *<0.05,0.0 \mathrm{I}$, 0.001 . 
endothelial injury related to aging. This was also accompanied by decreased protein expression of $\mathrm{Bcl}-2$ and increased protein expression of Bax and cleaved caspase 3 (Figure 1C). As expected, MLT treatment greatly reduced the apoptotic cells, accompanied with the elevated Bcl-2 expression and reduced Bax and cleaved caspase 3 expression (Figure 1B and $\mathrm{C}$ ).

\section{MLT Alleviates Vascular Aging-Related Inflammatory Response and Oxidative Stress in $\mathrm{ApoE}^{-/-}$Mice}

Given the powerful anti-inflammatory and antioxidant properties of MLT, we next evaluated the effects of MLT on inflammatory response and oxidative stress in $\mathrm{ApoE}^{-/-}$ mice. The pro-inflammatory cytokines, including IL-6, IL$1 \beta$ and TNF- $\alpha$, were hugely elevated no matter in blood or in blood vessel tissues upon HFD administration and were higher in aged mice than those in young mice; however, MLT treatment exhibited an inhibitory effect on the production of these inflammatory cytokines (Figure 2A and B). Moreover, the elevated reactive oxygen species (ROS) and malondialdehyde (MDA) and reduced superoxide dismutase (SOD) levels was observed in atherosclerotic mice or aged mice, indicating that oxidative stress occurred in atherosclerosis and aging worsened oxidative stress in atherosclerotic mice. These changes were then partly weakened by MLT treatment (Figure 2C-F). These results suggested that vascular aging aggravated inflammatory response and oxidative stress in $\mathrm{ApoE}^{-/-}$mice, which could be attenuated by MLT treatment.

\section{MLT Attenuates Senescence and Regulates Telomere-Telomerase Function in $\mathrm{ApoE}^{-/-}$Mice}

Given that CYP1A1 is one of the targeted genes of MLT by searching STITCH website (http://stitch.embl.de/) and is related to atherosclerosis progression and telomeretelomerase function, we then detected CYP1A1 activity in young and aged $\mathrm{ApoE}^{-/-}$mice with different treatment. As exhibited in Figure 3A, the CYP1A1 activity was elevated following HFD administration, but declined following MLT treatment. In addition, it was obvious that the CYP1A1 activity was higher in aged mice than that in young mice. The similar change trend was also observed on 15-HETE level (Figure 3B). Next, an obvious reduction of telomere length was observed in $\mathrm{ApoE}^{-/-}$mice following HFD administration compared to the control, especially in aged mice. The ameliorative effect of MLT on the shortened telomere was obvious in aged mice but limited in young mice (Figure 3C). Meanwhile, TERT activity was decreased following HFD administration, especially in aged mice, and MLT improved TERT activity in both young and aged mice (Figure 3D). In addition, the overall telomere length and TERT activity in aged mice were lower than those in young mice, suggesting that the telomere function was lowered upon aging in $\mathrm{ApoE}^{-/-}$ mice.

Moreover, as vascular aging is an important contributor to atherosclerosis, we also investigated the effect of MLT on senescence. It was observed that SA- $\beta$-gal, a classical marker of senescence, was slightly increased in young mice following HFD administration, but was hugely increased in aged mice compared to the young. MLT treatment slightly reduced the SA- $\beta$-gal level (Figure $3 \mathrm{E}$ and F). Furthermore, we also detected senescence-related protein expression. As shown in Figure 3G, the protein expression of cyclin D1 and cyclin-dependent kinase 2 (CDK2) was decreased, while the protein expression of p16 and p21 was increased in atherosclerotic mice, especially in the aged, which were then partly hindered by MLT treatment.

\section{MLT Alleviates Vascular Endothelial Injury by Regulating Senescence and Telomerase Activity}

Finally, we further verified our hypothesis by conducting cellular experiments. HUVECs were treated with RHPS4, an inhibitor of telomerase activity, along with or without MLT (100 $\mu \mathrm{M}$ (MLT-L) and $500 \mu \mathrm{M}$ (MLT-H)), $30 \mathrm{~min}$ prior to $\mathrm{H}_{2} \mathrm{O}_{2}$ induction. As shown in Figure $4 \mathrm{~A}$ and $\mathrm{B}$, $\mathrm{H}_{2} \mathrm{O}_{2}$ induction caused a great reduction of cell viability, which was much strengthened by RHPS4 treatment, indicating that senescence resulted in cell viability loss, which was aggravated by the inhibition of telomerase activity. However, the cell viability loss was alleviated by MLT treatment. Additionally, $\mathrm{H}_{2} \mathrm{O}_{2}$ induction resulted in a remarkably increased apoptosis rate of HUVECs, which was strengthened by RHPS4 treatment, accompanied with the increased protein expression of Bax and cleaved caspase 3 and decreased protein expression of Bcl-2, whereas these changes were partly reversed by MLT (Figure 4C and D), indicating that MLT could attenuate senescence- and telomerase dysfunction-caused endothelial cell viability loss and apoptosis. Moreover, 
A

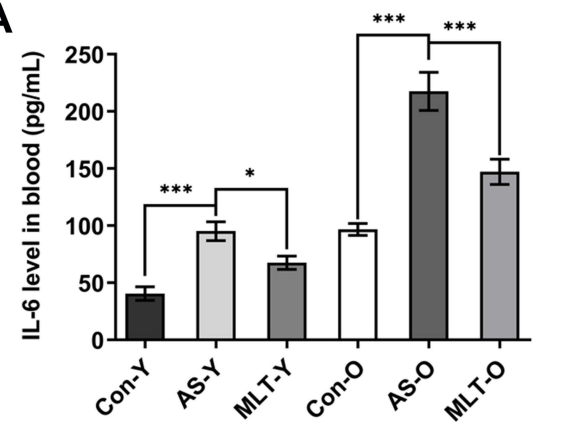

B

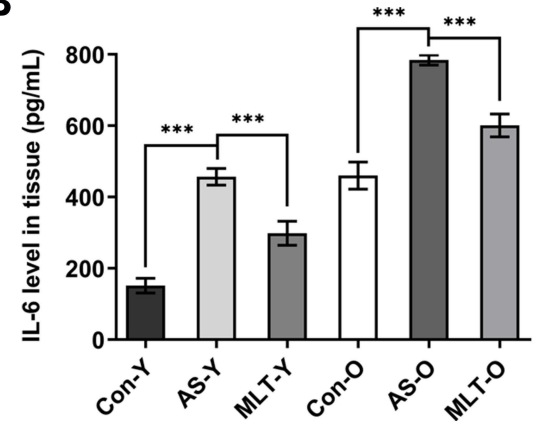

C
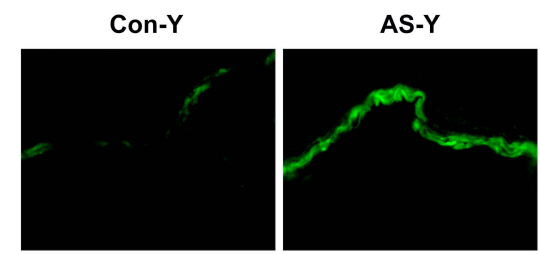

D

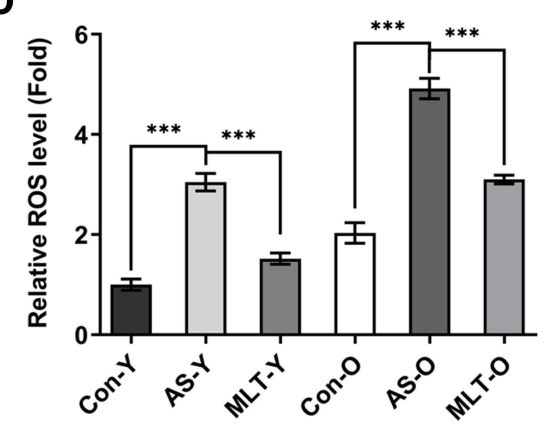

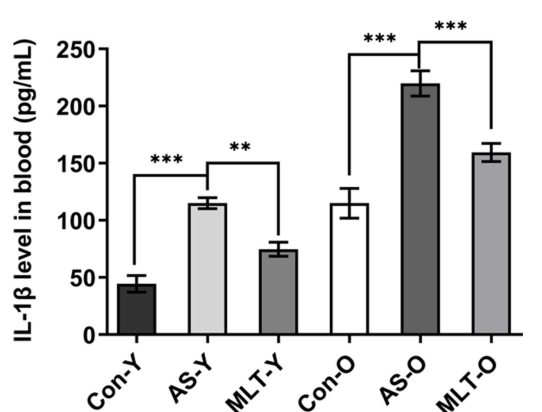
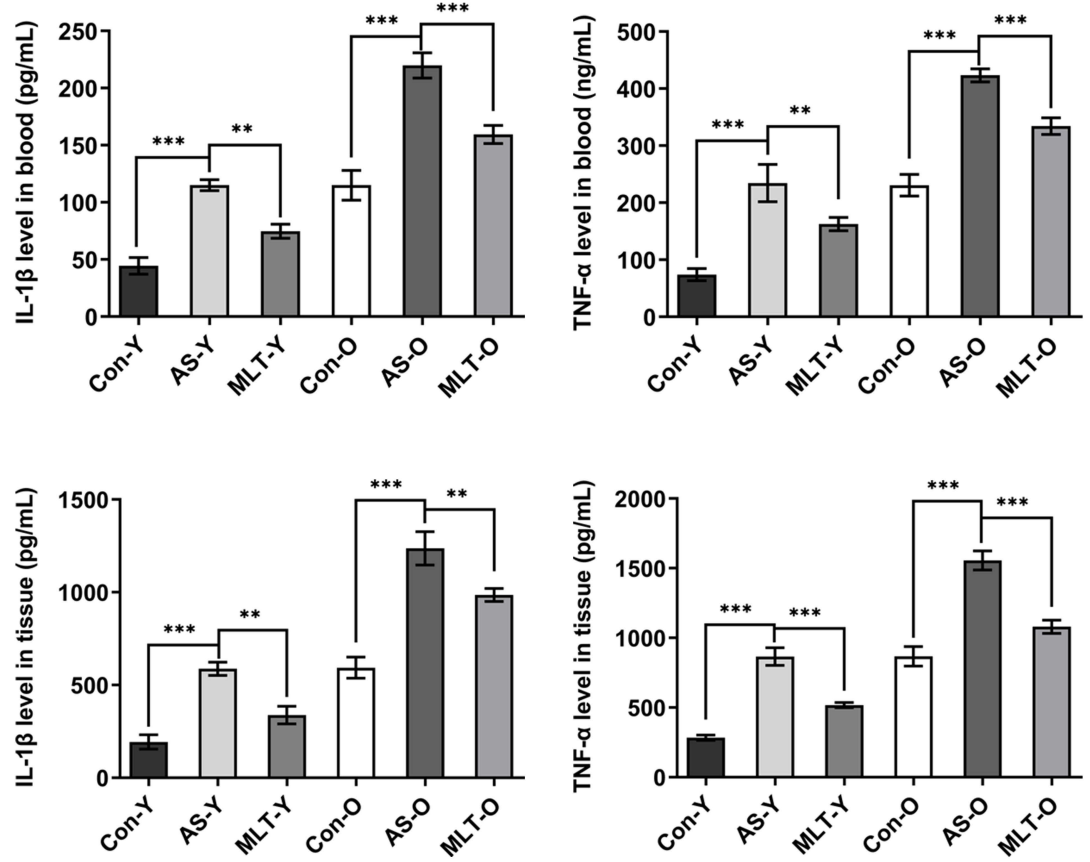

MLT-Y

Con-o
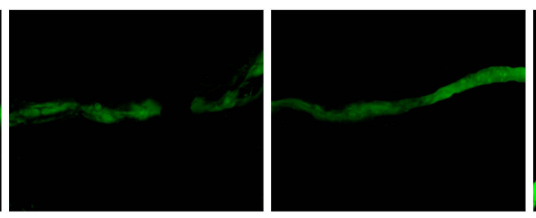

AS-O

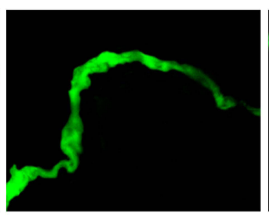

MLT-O

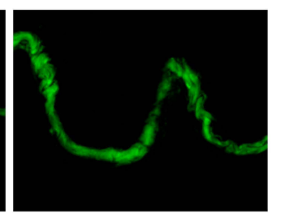

E

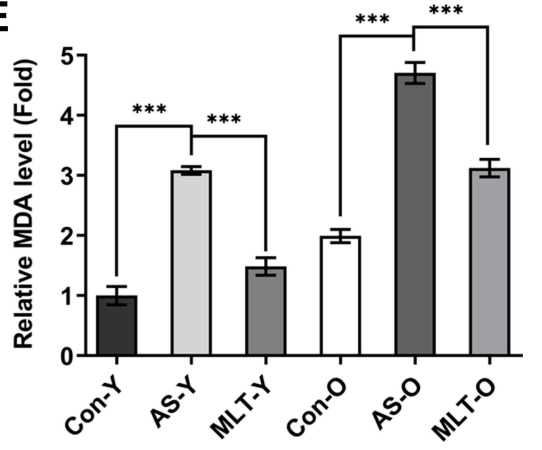

F

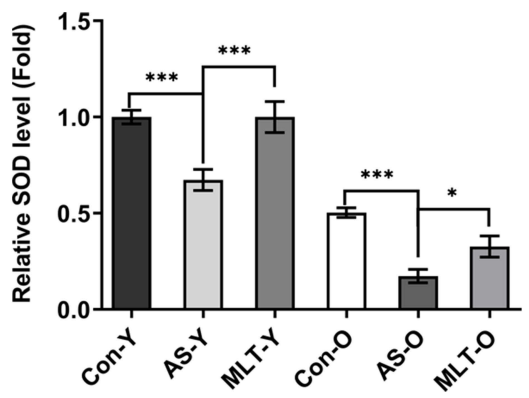

Figure 2 MLT alleviates vascular aging-related inflammatory response and oxidative stress in $\mathrm{ApoE}^{-1-}$ mice. Young-male ApoE ${ }^{-1-}$ mice and aged-male ApoE ${ }^{-1-}$ mice were received high fat diet (HFD) to induce atherosclerosis and intraperitoneally injected with melatonin (MLT; $20 \mathrm{mg} / \mathrm{kg} / \mathrm{d})$ for treatment. (A) ELISA assay on the proinflammatory cytokines, including IL-6, IL-I $\beta$ and TNF- $\alpha$ in blood. (B) ELISA analysis on the pro-inflammatory cytokines, including IL-6, IL-I $\beta$ and TNF- $\alpha$ in blood vessel tissues. (C and $\mathbf{D})$ The level of ROS in blood vessel tissues was detected using its assay kit. (E and $\mathbf{F}$ ) The level of MDA and SOD in blood vessel tissues was detected using their commercial kits. $\mathrm{N}=3$. *, **, *** $\mathrm{p}<0.05,0.01,0.001$.

CYP1A1 activity and TERT activity were increased following $\mathrm{H}_{2} \mathrm{O}_{2}$ induction and RHPS4 treatment, which were then hugely inhibited by MLT (Figure 5A and B). SA- $\beta$ gal level was greatly improved following $\mathrm{H}_{2} \mathrm{O}_{2}$ induction and RHPS4 treatment, and was then reduced by MLT treatment (Figure 5C and D). Furthermore, MLT upregulated the reduced protein expression of cyclin D1 and CDK2 and downregulated the elevated protein expression of p16 and p21 in HUVECs stimulated by $\mathrm{H}_{2} \mathrm{O}_{2}$ and RHPS4 (Figure 5E).

\section{Discussion}

Atherosclerosis is an aging-related disease. In particular, vascular endothelial cell aging takes responsibility for the progression of atherosclerosis. Preventing accelerated cellular senescence has been considered as a therapeutic 

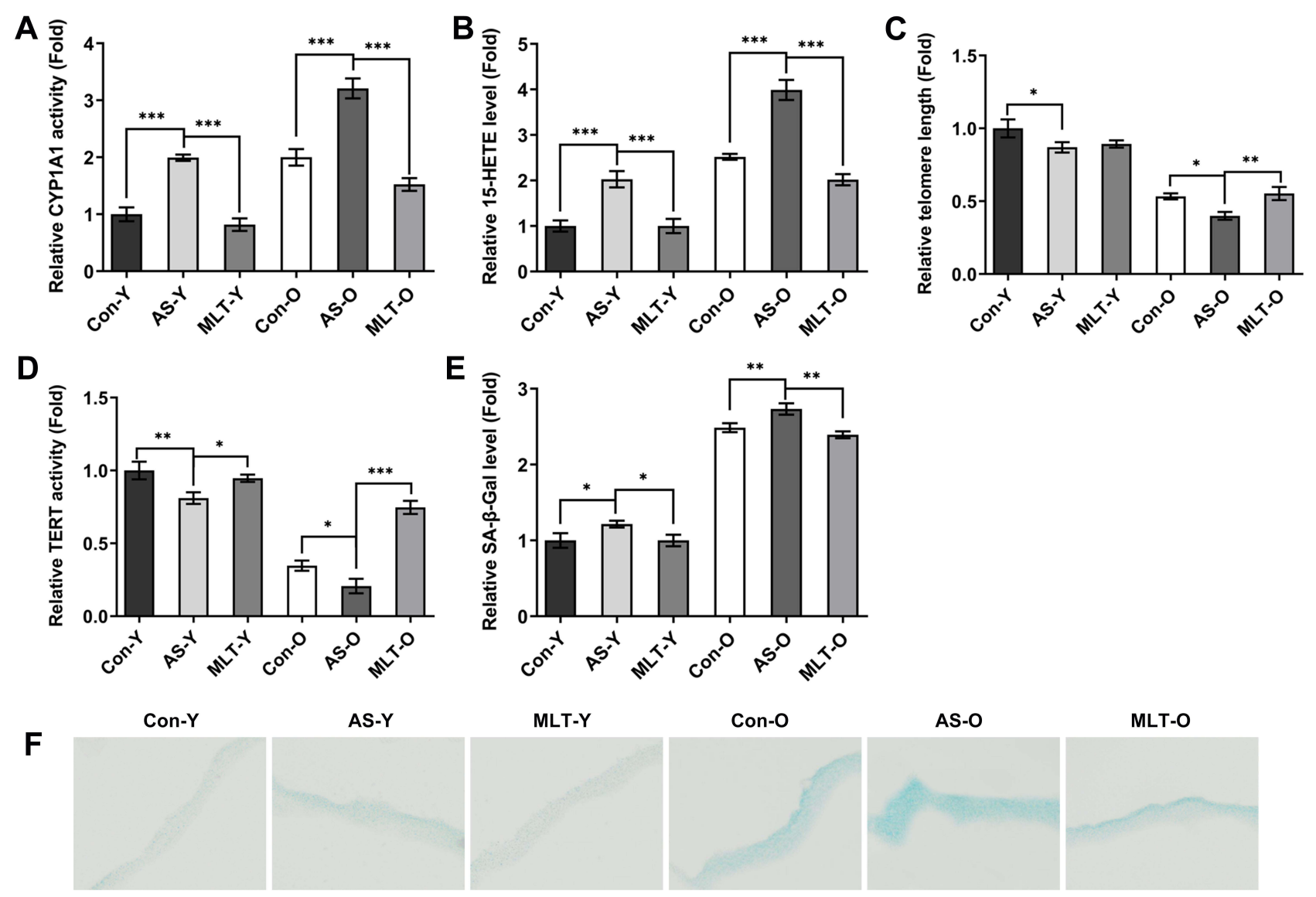

AS-O MLT-O

\section{G}
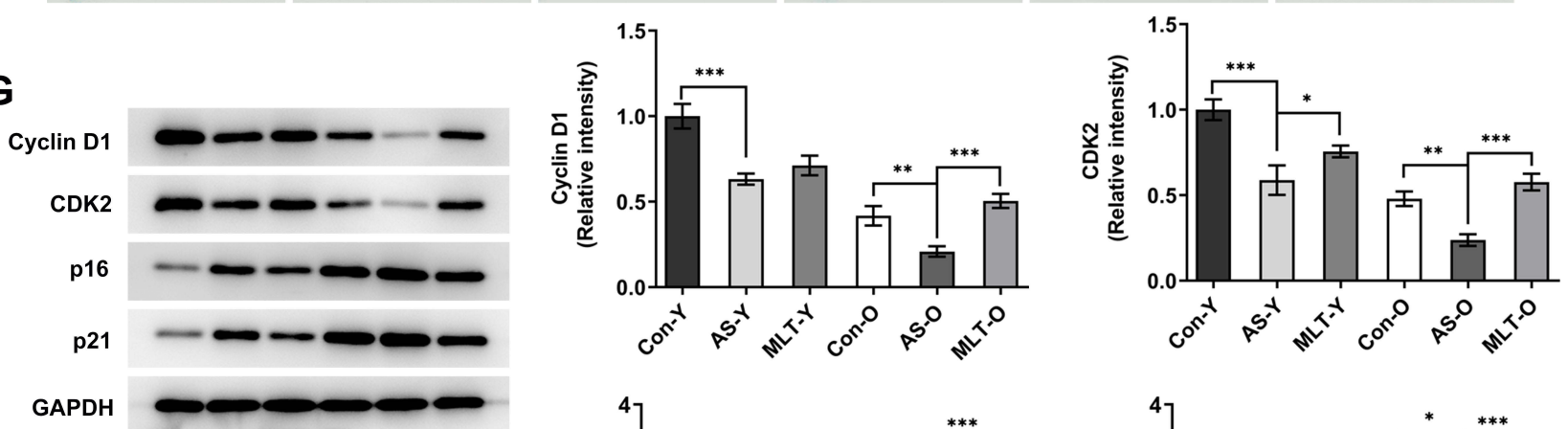

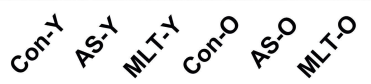
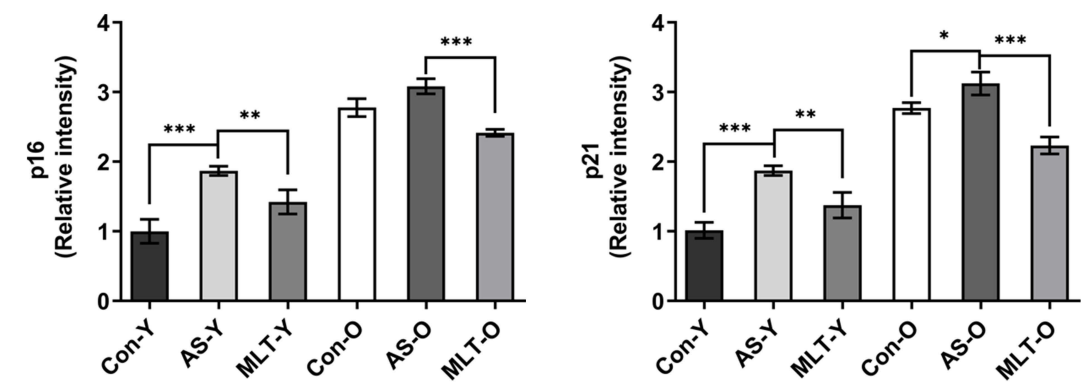

Figure $3 \mathrm{MLT}$ attenuates senescence and regulates telomere-telomerase function in $\mathrm{ApoE}^{-/-}$mice. Young-male $\mathrm{ApoE}^{-/-}$mice and aged-male $\mathrm{ApoE}^{-/-}$mice were received high fat diet (HFD) to induce atherosclerosis and intraperitoneally injected with melatonin (MLT; $20 \mathrm{mg} / \mathrm{kg} / \mathrm{d}$ ) for treatment. (A) CYPIAI activity was detected using P450Glo ${ }^{\mathrm{TM}}$ CYPIAI Assay kit. (B) ELISA analysis on the level of I5-HETE. (C) Telomere length measurements were performed by Southern blot analysis of the terminal restriction fragments. (D) Telomerase activity was detected by TRAP assay. (E and F) SA- $\beta$-gal Staining Kit was used to detect SA- $\beta$-gal level. (G) Western blot and statistical analysis of protein expression of cyclin DI, CDK2, pl6 and p2I. N=3. *, **, *** p $<0.05,0.01,0.001$. 
A

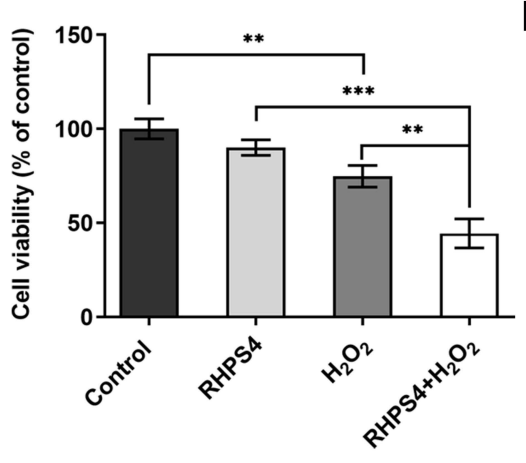

B

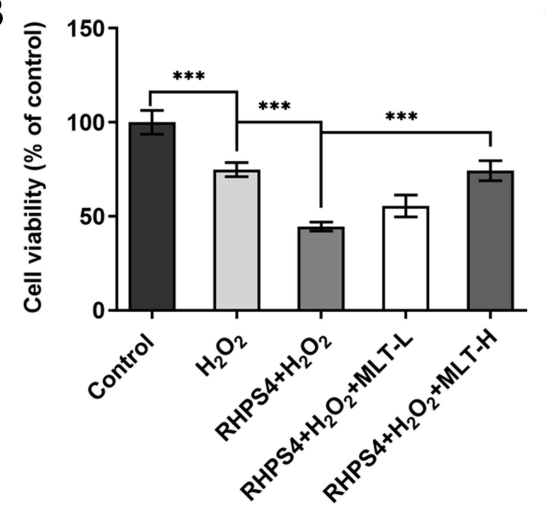

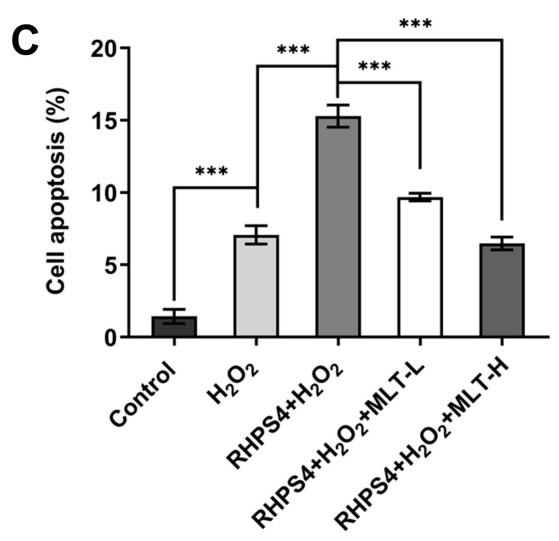

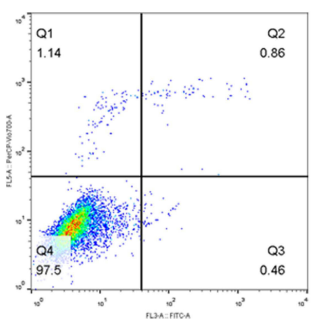

Control

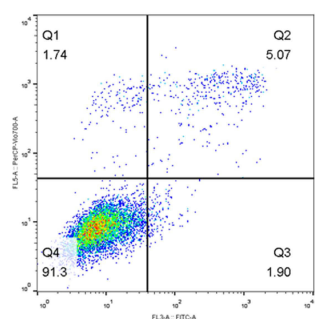

$\mathrm{H}_{2} \mathrm{O}_{2}$

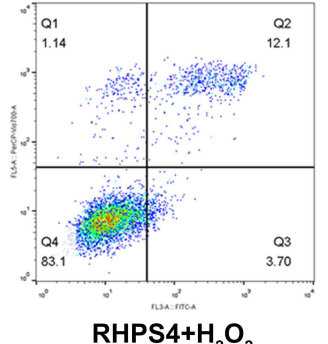

RHPS4 $+\mathrm{H}_{2} \mathrm{O}_{2}$

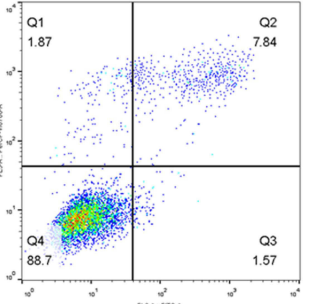

RHPS4 $+\mathrm{H}_{2} \mathrm{O}_{2}+$ MLT-L

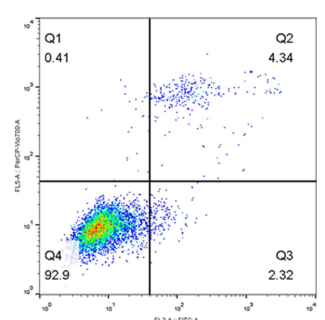

RHPS4 $+\mathrm{H}_{2} \mathrm{O}_{2}+$ MLT-H

D
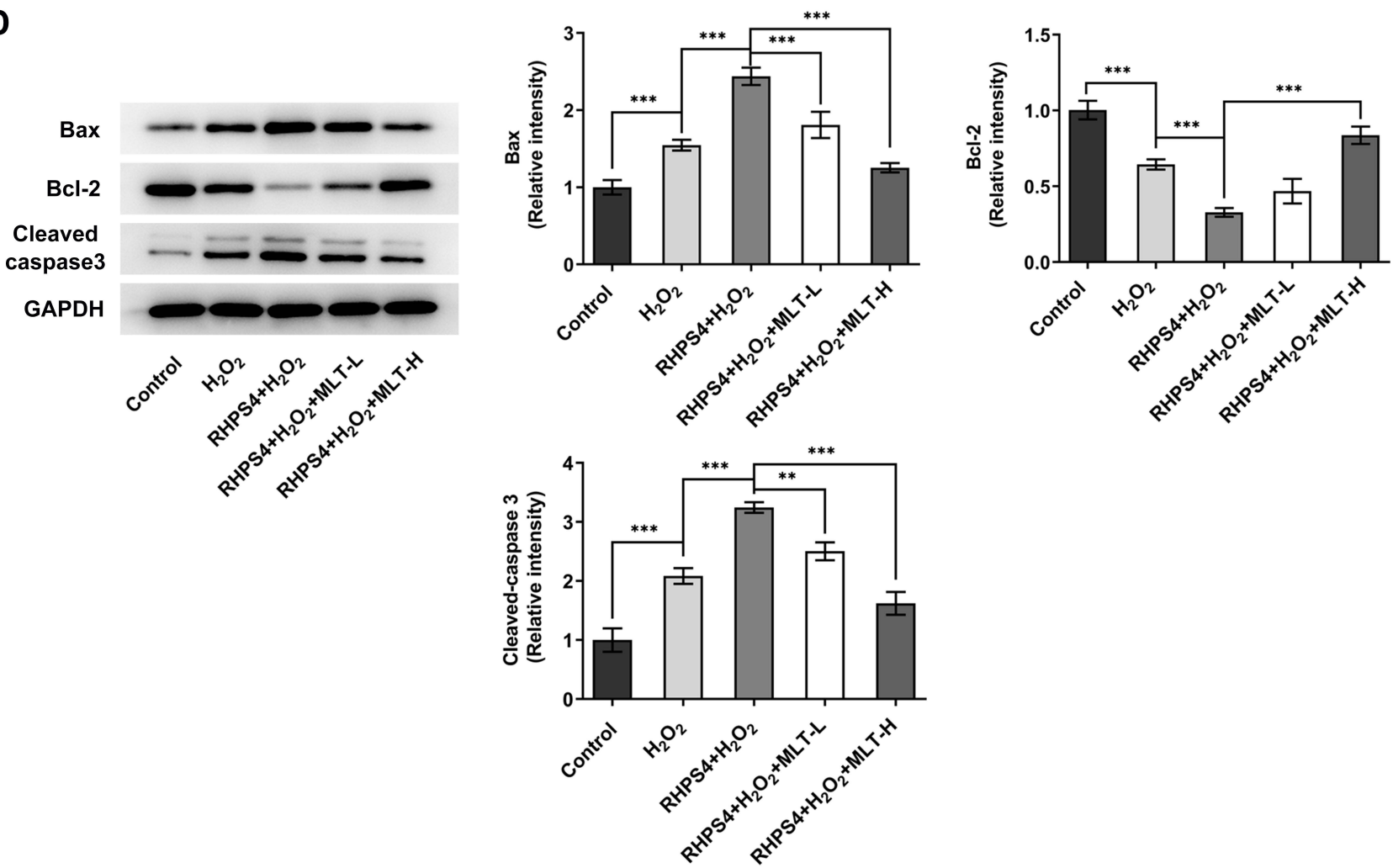

Figure 4 MLT alleviates cell apoptosis in HUVECs treated by $\mathrm{H}_{2} \mathrm{O}_{2}$ and RHPS4 HUVECs were treated with RHPS4, an inhibitor of telomerase activity, along with or without MLT (I00 $\mu$ M (MLT-L) and $500 \mu \mathrm{M}(\mathrm{MLT}-\mathrm{H})$ ), $30 \mathrm{~min}$ prior to $\mathrm{H}_{2} \mathrm{O}_{2}$ induction. (A and B) cell viability was detected using MTT assay. (C) Flow cytometry assay and statistical assay on cell apoptosis. (D) Western blot and statistical analysis of protein expression of $\mathrm{Bax}, \mathrm{Bcl}-2$ and cleaved caspase3. $\mathrm{N}=3$. $* *, * * * \mathrm{p}<0.0 \mathrm{I}, 0.00 \mathrm{I}$. 


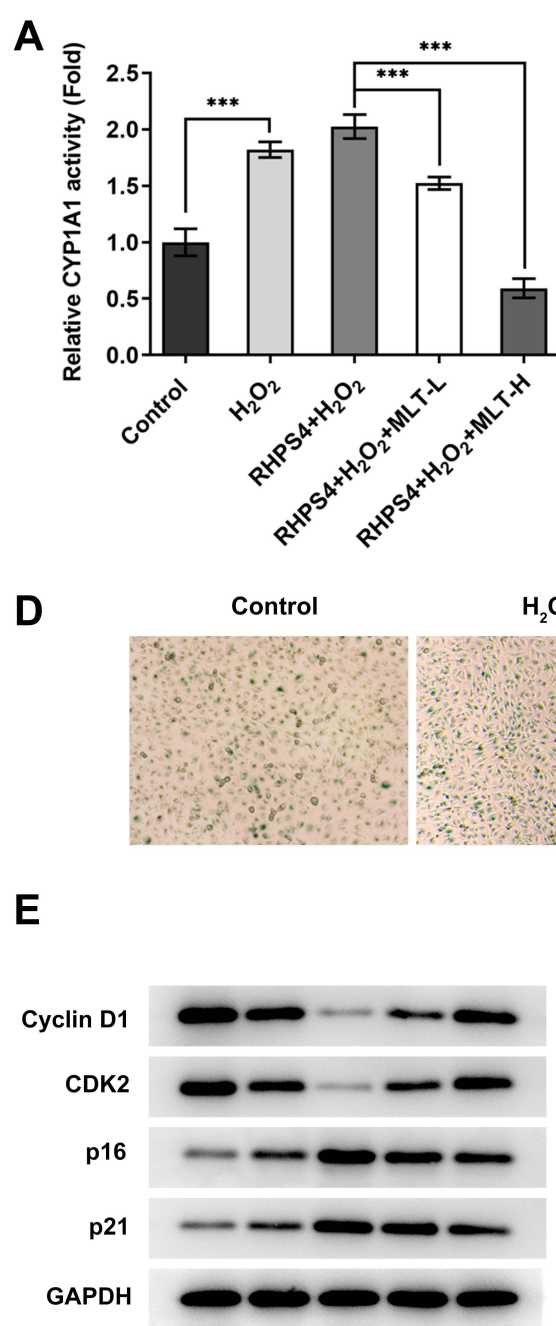

B

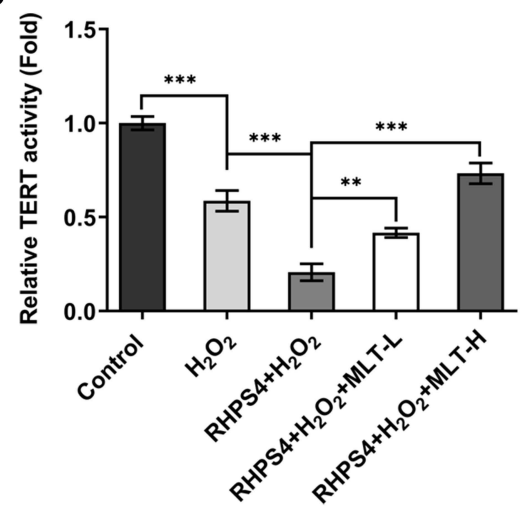

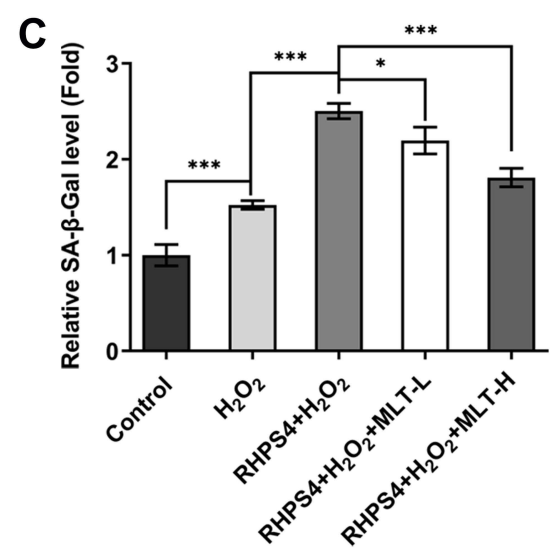

$\mathrm{H}_{2} \mathrm{O}_{2}$

RHPS4+ $\mathrm{H}_{2} \mathrm{O}_{2}$

RHPS4 $+\mathrm{H}_{2} \mathrm{O}_{2}+\mathrm{MLT}-\mathrm{L} \quad \mathrm{RHPS} 4+\mathrm{H}_{2} \mathrm{O}_{2}+\mathrm{MLT}-\mathrm{H}$
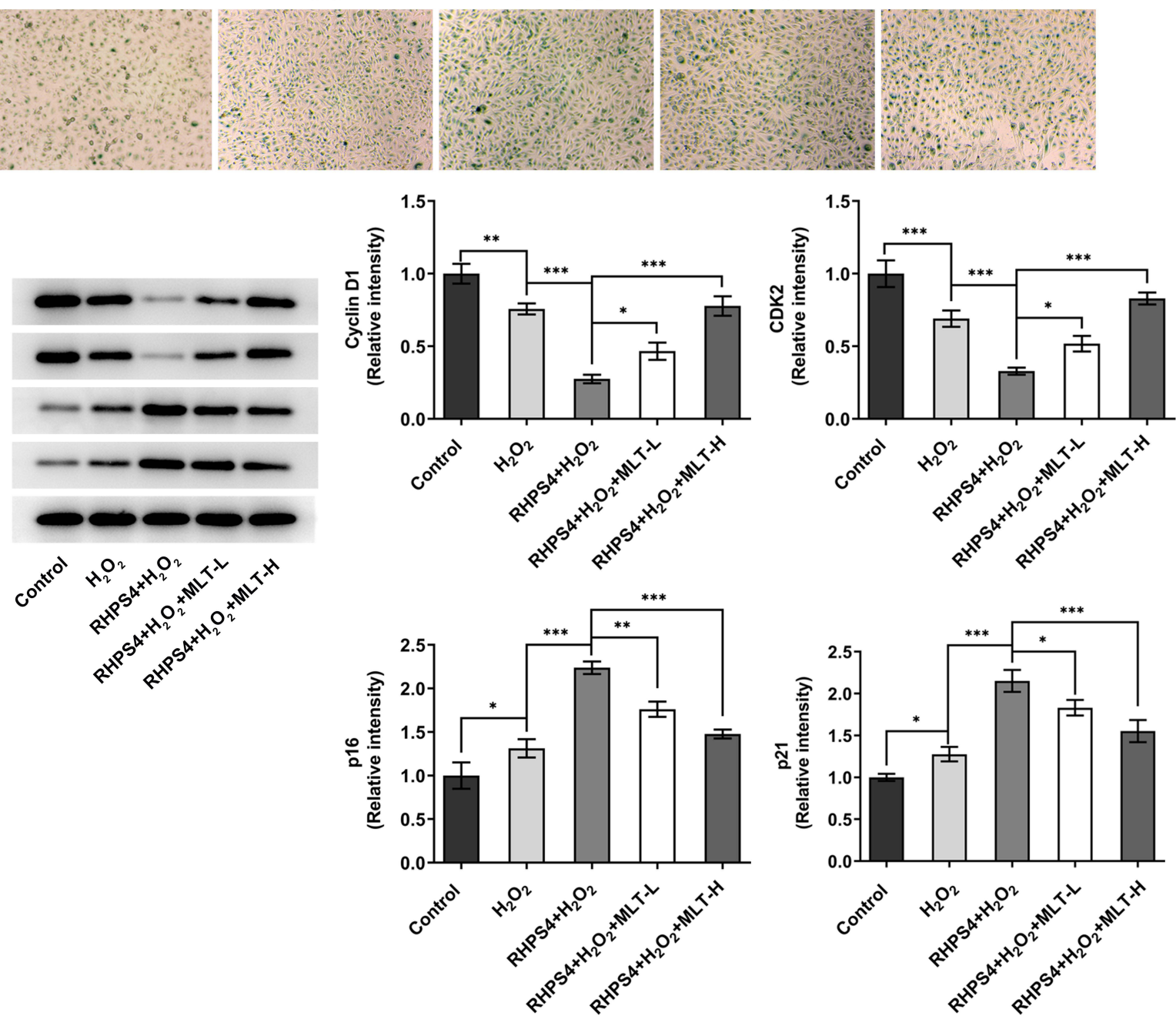

Figure 5 MLT inhibits senescence and improves telomerase activity in HUVECs treated by $\mathrm{H}_{2} \mathrm{O}_{2}$ and RHPS4 HUVECs were treated with RHPS4, an inhibitor of telomerase activity, along with or without MLT ( $100 \mu \mathrm{M}$ (MLT-L) and $500 \mu \mathrm{M}$ (MLT-H)), 30 min prior to $\mathrm{H}_{2} \mathrm{O}_{2}$ induction. (A) CYPIAI activity was detected using P450-Glo ${ }^{\text {TM }}$ CYPIAI Assay kit. (B) Telomerase activity was detected by TRAP assay. (C and D) SA- $\beta$-gal Staining Kit was used to detect SA- $\beta$-gal level. (E) Western blot and statistical analysis of protein expression of cyclin DI, CDK2, pl6 and p2I. N=3. *, **, *** $<<0.05,0.01,0.001$. 
target in atherosclerosis. ${ }^{26}$ In the present study, we demonstrated that the endothelial injury was more severe in aged atherosclerotic mice than that in young mice. MLT alleviated endothelial injury by inhibiting inflammatory response, oxidative stress and cell apoptosis in atherosclerosis. Of note, MLT exerted strongly inhibitory effect on cellular senescence in aging-related vascular endothelial cells in atherosclerosis. In addition, MLT had a positive improvement on telomere length and telomerase activity, which might partly explain the potential mechanism by which MLT attenuated senescence in atherosclerosis.

Emerging evidence show that telomerase dysfunction is closely associated with the risk of atherosclerosis and is an important reason contributing to vascular endothelial cell senescence in human atherosclerosis. ${ }^{27}$ Upregulation of telomerase might be a potential new strategy to prevent or delay atherosclerosis. ${ }^{28}$ hTERT, the critical subunit of telomerase to counteract telomeres shortening, can extend cell lifespan and telomeres to lengths typically of those in young cells. ${ }^{29,30}$ Thus, the high activity of hTERT is beneficial to maintain telomerase activity and telomeres length, contributing to chromosome stability and cellular immortalization. It has been evidenced that hTERT expression was regulated by MLT, but the effect of MLT on hTERT expression or telomerase activity was discrepant in different diseases. For example, the hTERT was highly active in tumors and MLT could exert its anti-tumor activity by inhibiting the expression of hTERT and the activity of telomerase. ${ }^{31,32}$ In contrast, in age-related macular degeneration, an eye disease, the telomere synthesis was inhibited by oxidative stress stimulation, while MLT could overcome this inhibition by stimulating the activity of telomerase and rebuilding the telomeres. ${ }^{33}$ Accordingly, in the present study, the reduced TERT activity and shortened telomere length were observed in aged atherosclerotic mice in vivo or $\mathrm{H}_{2} \mathrm{O}_{2}$-induced HUVECs in vitro, while MLT could restrain these changes, indicating that MLT might attenuate atherosclerosis through improving telomerase activity.

Next, further attention was paid on the specific molecular mechanism underlying the regulatory role of MLT in atherosclerosis. Intriguingly, CYP1A1, which is related to atherosclerosis progression and telomere-telomerase function, is found to be one of the targeted genes of MLT by searching STITCH website (http://stitch.embl.de/). CYP1A1 is a member of a multigenic family of xenobiotic-metabolizing enzymes and is deleterious as it can generate mutagenic metabolites, lipid peroxidation and oxidative stress. ${ }^{34,35}$ Thus, the inhibitory effects of MLT on CYP1A1, inflammatory response and oxidative stress in atherosclerotic mice in this study indicated that the antioxidant activity and anti-inflammatory activity of MLT might be partly dependent on the reduced CYP1A1 expression. In addition, CYP1A1 was also regarded as a key enzyme in the metabolic pathway of arachidonic acid, which could transform arachidonic acid into 15hydroxyeicosatetraenoic acid (15-HETE). ${ }^{36}$ On one hand, 15-HETE was associated with general lipid oxidation and ROS-dependent apoptosis. ${ }^{37,38}$ On the other hand, the generation of 15-HETE could promote hTERT expression, and the high level of TERT in turn induced the synthesis of 15-HETE. ${ }^{39}$ Accordingly, MLT might regulate telomerase activity by targeting CYP1A1-mediated 15-HETE/TERT pathway. In the present study, the high level of CYP1A1 and 15-HETE was verified in atherosclerotic and aged mice in vivo, and in $\mathrm{H}_{2} \mathrm{O}_{2}$-induced HUVECs in vitro, which were partly abolished by MLT treatment; however, hTERT changes in the opposite direction to 15-HETE. The possible reason is that telomerase activity has a greater influence on TERT than CYP1A1, indicating that the inhibitory effect of MLT on endothelial injury in atherosclerosis partly accounts for the targeting regulation of CYP1A1, but not dominantly.

Emerging evidence uncovered that accelerated biological aging can be promoted by cardiovascular risk factor and demonstrated the accelerated vascular aging in atherosclerosis. ${ }^{40}$ Cellular senescence is also observed in patients with atherosclerosis, especially in advanced plaques. Atherosclerosis is regarded as a disease both cellular senescence and organismal aging. ${ }^{26,27}$ Here, we found a high level of SA- $\beta$-gal and high protein expression of p16 and p21, accompanied with the low protein expression of CDK2 and cyclinD1 in atherosclerotic mice, especially in aged mice in vivo, and $\mathrm{H}_{2} \mathrm{O}_{2}$ induced senescent model in vitro. p53-p21 and p16 are two predominate pathways controlling senescence, which are easily activated by telomere shorteninginduced DNA damage response and by multiple stressors such as inflammation and oxidative stress during the aging process. As CDK inhibitors, the activation of p21 and p16 then leads to the inhibition of CDK2 and cyclinD1. $^{41-43}$ Therefore, senescence phenomenon did exist in vascular endothelial injury in atherosclerosis, especially in aged mice, which might be associated with the dysfunction of telomere and excessive 
accumulation of pro-inflammatory cytokines and lipid peroxide. Recent studies have shown that telomere repair is an important term to interfere cell senescence and prevent atherosclerosis. For example, in vitro recombinant expression of TERT can prolong the survival time of vascular smooth muscle cells (VSMC) in atherosclerotic plaques, while inhibition of TERT can terminate the proliferation of VSMC, leading to the reduction of the regeneration of damaged vascular intima. $^{44}$ In addition, activation of telomeric repeat binding factor 2 (TRF2), namely telomeric protective protein, can inhibit the aging process of vascular endothelium, enhance the repair ability of damaged DNA, protect vascular intima and increase plaque stability. $^{45}$ As expected, MLT, which has been demonstrated to improve telomerase activity as stated before, was also found to have the ability to inhibit senescence as it greatly reduced SA- $\beta$-gal level and protein expression of $\mathrm{p} 16$ and $\mathrm{p} 21$, as well as increasing protein expression of CDK2 and cyclinD1 in injured endothelial cells and tissues. Therefore, the properties of antiinflammation, anti-oxidant, and promoting telomerase activity of MLT jointly contributed to its protective effect on vascular aging-related atherosclerosis.

\section{Conclusion}

Altogether, to the best of our knowledge, it might be the first time to report that MLT alleviated vascular aging by improving telomerase activity in atherosclerosis. In addition, MLT greatly inhibited the inflammatory response, oxidative stress and cell apoptosis in vascular endothelial injury in atherosclerosis partly by regulating CYP1A1 activity. The properties of anti-inflammation, anti-oxidant, and promoting telomerase activity of MLT jointly contributed to its protective effect on vascular aging-related atherosclerosis. This study further deepens the potential therapeutic role of MLT in atherosclerosis, providing certain scientific and clinical significance for MLT application.

\section{Data Sharing Statement}

All data generated or analyzed during this study are included in this published article.

\section{Ethics Statement}

This study was carried out according to the Guide for the Care and Use of Laboratory animals and approved by the Ethics Committee of the Nanjing First Hospital.

\section{Funding}

This study was supported by Jiangsu Provincial Key Research and Development Program (No. BE2018611).

\section{Disclosure}

The authors declare that they have no known competing financial interests or personal relationships that could have appeared to influence the work reported in this paper.

\section{References}

1. Bentzon JF, Otsuka F, Virmani R, Falk E. Mechanisms of plaque formation and rupture. Circ Res. 2014;114(12):1852-1866. doi:10.1161/CIRCRESAHA.114.302721

2. Liu Y, Chen KJ. Atherosclerosis, vascular aging and therapeutic strategies. Chin J Integr Med. 2012;18(2):83-87. doi:10.1007/ s11655-012-0996-z

3. Perk J, De Backer G, Gohlke H, et al. European Guidelines on cardiovascular disease prevention in clinical practice (version 2012). The Fifth Joint Task Force of the European Society of Cardiology and Other Societies on Cardiovascular Disease Prevention in Clinical Practice (constituted by representatives of nine societies and by invited experts). Eur Heart J. 2012;33 (13):1635-1701. doi:10.1093/eurheartj/ehs092

4. Benjamin EJ, Virani SS, Callaway CW, et al. Heart disease and stroke statistics-2018 update: a report from the American Heart Association. Circulation. 2018;137(12):e67-e492. doi:10.1161/CIR.000000000 0000558

5. Sturlaugsdottir R, Aspelund T, Bjornsdottir G, et al. Prevalence and determinants of carotid plaque in the cross-sectional REFINE-Reykjavik study. BMJ Open. 2016;6(11):e012457. doi:10.1136/bmjopen-2016012457

6. Shay JW, Wright WE. Telomeres and telomerase: three decades of progress. Nat Rev Genet. 2019;20(5):299-309. doi:10.1038/s41576019-0099-1

7. Minamino T, Komuro I. Role of telomere in endothelial dysfunction in atherosclerosis. Curr Opin Lipidol. 2002;13(5):537-543. doi:10.1097/00041433-200210000-00010

8. Minamino T, Miyauchi H, Yoshida T, Komuro I. Endothelial cell senescence in human atherosclerosis: role of telomeres in endothelial dysfunction. J Cardiol. 2003;41(1):39-40.

9. Doshida M, Ohmichi M, Tsutsumi S, et al. Raloxifene increases proliferation and up-regulates telomerase activity in human umbilical vein endothelial cells. J Biol Chem. 2006;281(34):24270-24278. doi:10.1074/jbc.M513251200

10. Bennaceur K, Atwill M, Al Zhrany N, et al. Atorvastatin induces $\mathrm{T}$ cell proliferation by a telomerase reverse transcriptase (TERT) mediated mechanism. Atherosclerosis. 2014;236(2):312-320. doi:10.1016/j.atherosclerosis.2014.07.020

11. Pu DR, Liu L. HDL slowing down endothelial progenitor cells senescence: a novel anti-atherogenic property of HDL. Med Hypotheses. 2008;70(2):338-342. doi:10.1016/j.mehy.2007.05.025

12. Anderson G, Vaillancourt C, Maes M, Reiter RJ. Breastfeeding and the gut-brain axis: is there a role for melatonin? Biomol Concepts. 2017;8(3-4):185-195. doi:10.1515/bmc-2017-0009

13. Yang Y, Sun Y, Yi W, et al. A review of melatonin as a suitable antioxidant against myocardial ischemia-reperfusion injury and clinical heart diseases. J Pineal Res. 2014;57(4):357-366. doi:10.1111/ jpi. 12175

14. Hu ZP, Fang XL, Fang N, et al. Melatonin ameliorates vascular endothelial dysfunction, inflammation, and atherosclerosis by suppressing the TLR4/NF-kappaB system in high-fat-fed rabbits. J Pineal Res. 2013;55(4):388-398. doi:10.1111/jpi.12085 
15. Hung MW, Kravtsov GM, Lau CF, Poon AM, Tipoe GL, Fung ML. Melatonin ameliorates endothelial dysfunction, vascular inflammation, and systemic hypertension in rats with chronic intermittent hypoxia. J Pineal Res. 2013;55(3):247-256. doi:10.1111/jpi.12067

16. Dominguez-Rodriguez A, Abreu-Gonzalez P, Reiter RJ. The potential usefulness of serum melatonin level to predict heart failure in patients with hypertensive cardiomyopathy. Int $J$ Cardiol. 2014;174 (2):415-417. doi:10.1016/j.ijcard.2014.04.044

17. Bhattacharya S, Patel KK, Dehari D, Agrawal AK, Singh S. Melatonin and its ubiquitous anticancer effects. Mol Cell Biochem. 2019;462(1-2):133-155. doi:10.1007/s11010-019-03617-5

18. Habtemariam S, Daglia M, Sureda A, Selamoglu Z, Gulhan MF, Nabavi SM. Melatonin and respiratory diseases: a review. Curr Top Med Chem. 2017;17(4):467-488. doi:10.2174/15680266166661 60824120338

19. Chen D, Zhang T, Lee TH. Cellular mechanisms of melatonin: insight from neurodegenerative diseases. Biomolecules. 2020;10(8):Aug. doi:10.3390/biom 10081158

20. Miller KP, Ramos KS. Impact of cellular metabolism on the biological effects of benzo[a]pyrene and related hydrocarbons. Drug Metab Rev. 2001;33(1):1-35. doi:10.1081/dmr-100000138

21. Iwano S, Asanuma F, Nukaya M, Saito T, Kamataki T. CYP1A1mediated mechanism for atherosclerosis induced by polycyclic aromatic hydrocarbons. Biochem Biophys Res Commun. 2005;337 (2):708-712. doi:10.1016/j.bbrc.2005.09.109

22. Mohammed K, Shervington A. Can CYP1A1 siRNA be an effective treatment for lung cancer? Cell Mol Biol Lett. 2008;13(2):240-249. doi:10.2478/s11658-007-0050-x

23. Kimura M, Stone RC, Hunt SC, et al. Measurement of telomere length by the Southern blot analysis of terminal restriction fragment lengths. Nat Protoc. 2010;5(9):1596-1607. doi:10.1038/ nprot.2010.124

24. Kim NW, Piatyszek MA, Prowse KR, et al. Specific association of human telomerase activity with immortal cells and cancer. Science. 1994;266(5193):2011-2015. doi:10.1126/science.7605428

25. Zheng $Z$, Wang $M$, Cheng $C$, et al. Ginsenoside $\mathrm{Rb} 1$ reduces H2O2induced HUVEC dysfunction by stimulating the sirtuin-1/ AMPactivated protein kinase pathway. Mol Med Rep. 2020;22 (1):247-256. doi:10.3892/mmr.2020.11096

26. Wang JC, Bennett M. Aging and atherosclerosis: mechanisms, functional consequences, and potential therapeutics for cellular senescence. Circ Res. 2012;111(2):245-259. doi:10.1161/ CIRCRESAHA.111.261388

27. Minamino T, Miyauchi H, Yoshida T, Ishida Y, Yoshida H, Komuro I. Endothelial cell senescence in human atherosclerosis: role of telomere in endothelial dysfunction. Circulation. 2002;105 (13):1541-1544. doi:10.1161/01.cir.0000013836.85741.17

28. Nazari-Shafti TZ, Cooke JP. Telomerase therapy to reverse cardiovascular senescence. Methodist DeBakey Cardiovasc J. 2015;11 (3):172-175. doi:10.14797/mdcj-11-3-172

29. Hsiao R, Sharma HW, Ramakrishnan S, Keith E, Narayanan R. Telomerase activity in normal human endothelial cells. Anticancer Res. 1997;17(2A):827-832.

30. Yang J, Chang E, Cherry AM, et al. Human endothelial cell life extension by telomerase expression. J Biol Chem. 1999;274 (37):26141-26148. doi:10.1074/jbc.274.37.26141

31. Zhang $\mathrm{H}, \mathrm{Hu} \mathrm{N}$. Telomerase reverse transcriptase induced thyroid carcinoma cell proliferation through PTEN/AKT signaling pathway. Mol Med Rep. 2018;18(2):1345-1352. doi:10.3892/mmr.2018.9119
32. Martinez-Campa CM, Alonso-Gonzalez C, Mediavilla MD, Cos S, Gonzalez A, Sanchez-Barcelo EJ. Melatonin down-regulates hTERT expression induced by either natural estrogens (17beta-estradiol) or metalloestrogens (cadmium) in MCF-7 human breast cancer cells. Cancer Lett. 2008;268(2):272-277. doi:10.1016/j.canlet.2008.04.001

33. Blasiak J, Reiter RJ, Kaarniranta K. Melatonin in retinal physiology and pathology: the case of age-related macular degeneration. Oxid Med Cell Longev. 2016;2016:6819736. doi:10.1155/2016/6819736

34. Barouki R, Morel Y. Repression of cytochrome P450 1A1 gene expression by oxidative stress: mechanisms and biological implications. Biochem Pharmacol. 2001;61(5):511-516. doi:10.1016/s0006-2952(00)00543-8

35. Huang B, Bao J, Cao YR, Gao HF, Jin Y. Cytochrome P450 1A1 (CYP1A1) catalyzes lipid peroxidation of oleic acid-induced HepG2 cells. Biochemistry (Mosc). 2018;83(5):595-602. doi:10.1134/ S0006297918050127

36. Lefevre L, Authier H, Stein S, et al. LRH-1 mediates anti-inflammatory and antifungal phenotype of IL-13-activated macrophages through the PPARgamma ligand synthesis. Nat Commun. 2015;6:6801. doi:10.1038/ncomms7801

37. Kahn-Kirby AH, Amagata A, Maeder CI, et al. Targeting ferroptosis: a novel therapeutic strategy for the treatment of mitochondrial disease-related epilepsy. PLoS One. 2019;14(3):e0214250. doi:10.1371/journal.pone.0214250

38. Mahipal SV, Subhashini J, Reddy MC, et al. Effect of 15-lipoxygenase metabolites, 15-(S)-HPETE and 15-(S)-HETE on chronic myelogenous leukemia cell line K-562: reactive oxygen species (ROS) mediate caspase-dependent apoptosis. Biochem Pharmacol. 2007;74(2):202-214. doi:10.1016/j.bcp.2007.04.005

39. Shen T, Ma J, Zhang L, et al. Positive feedback-loop of telomerase reverse transcriptase and 15-lipoxygenase-2 promotes pulmonary hypertension. PLoS One. 2013;8(12):e83132. doi:10.1371/journal. pone. 0083132

40. Farhat N, Thorin-Trescases N, Voghel G, et al. Stress-induced senescence predominates in endothelial cells isolated from atherosclerotic chronic smokers. Can J Physiol Pharmacol. 2008;86(11):761-769. doi:10.1139/Y08-082

41. Herbig U, Jobling WA, Chen BP, Chen DJ, Sedivy JM. Telomere shortening triggers senescence of human cells through a pathway involving ATM, p53, and p21(CIP1), but not p16(INK4a). Mol Cell. 2004;14(4):501-513. doi:10.1016/s1097-2765(04)00256-4

42. Purvis JE, Karhohs KW, Mock C, Batchelor E, Loewer A, Lahav G. p53 dynamics control cell fate. Science. 2012;336(6087):1440-1444. doi:10.1126/science.1218351

43. Chi C, Li DJ, Jiang YJ, et al. Vascular smooth muscle cell senescence and age-related diseases: state of the art. Biochim Biophys Acta Mol Basis Dis. 2019;1865(7):1810-1821. doi:10.1016/j.bbadis.2018. 08.015

44. Endorf EB, Qing H, Aono J, et al. Telomerase reverse transcriptase deficiency prevents neointima formation through chromatin silencing of E2F1 target genes. Arterioscler Thromb Vasc Biol. 2017;37 (2):301-311. doi:10.1161/ATVBAHA.116.308717

45. Wang J, Uryga AK, Reinhold J, et al. Vascular smooth muscle cell senescence promotes atherosclerosis and features of plaque vulnerability. Circulation. 2015;132(20):1909-1919. doi:10.1161/ CIRCULATIONAHA.115.016457 


\section{Publish your work in this journal}

The Journal of Inflammation Research is an international, peerreviewed open-access journal that welcomes laboratory and clinical findings on the molecular basis, cell biology and pharmacology of inflammation including original research, reviews, symposium reports, hypothesis formation and commentaries on: acute/chronic inflammation; mediators of inflammation; cellular processes; molecular mechanisms; pharmacology and novel anti-inflammatory drugs; clinical conditions involving inflammation. The manuscript management system is completely online and includes a very quick and fair peerreview system. Visit http://www.dovepress.com/testimonials.php to read real quotes from published authors.

Submit your manuscript here: https://www.dovepress.com/journal-of-inflammation-research-journal 